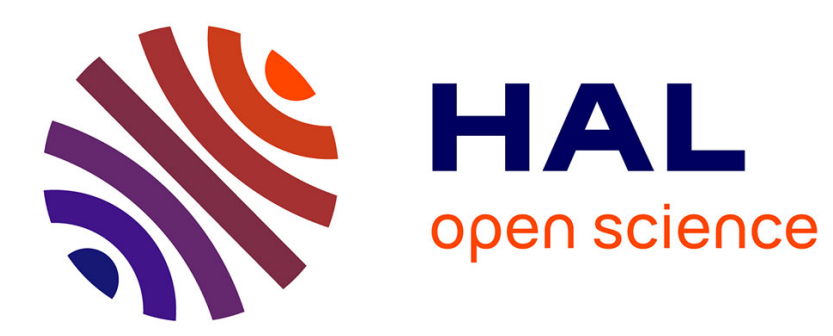

\title{
THE EFFECT OF CARBON BEARING GASES AND SECONDARY ELECTRON BOMBARDMENT ON A LIQUID METAL ION SOURCE
}

\author{
P. Sudraud, Jean Orloff, Gérard Benassayag
}

\section{- To cite this version:}

P. Sudraud, Jean Orloff, Gérard Benassayag. THE EFFECT OF CARBON BEARING GASES AND SECONDARY ELECTRON BOMBARDMENT ON A LIQUID METAL ION SOURCE. Journal de Physique Colloques, 1986, 47 (C7), pp.C7-381-C7-387. 10.1051/jphyscol:1986765 . jpa-00225960

HAL Id: jpa-00225960 https://hal.science/jpa-00225960

Submitted on 1 Jan 1986

HAL is a multi-disciplinary open access archive for the deposit and dissemination of scientific research documents, whether they are published or not. The documents may come from teaching and research institutions in France or abroad, or from public or private research centers.
L'archive ouverte pluridisciplinaire HAL, est destinée au dépôt et à la diffusion de documents scientifiques de niveau recherche, publiés ou non, émanant des établissements d'enseignement et de recherche français ou étrangers, des laboratoires publics ou privés. 


\title{
THE EFFECT OF CARBON BEARING GASES AND SECONDARY ELECTRON BOMBARDMENT ON A LIQUID METAL ION SOURCE
}

\author{
P. SUDRAUd, J. ORLOFF* and G. BENASSAYAG \\ Laboratoire de Microstructures et de Microelectronique, \\ Groupement Scientifique CNET-CNRS, 196, Rue Henri Ravera, \\ F-92220 Bagneux, France \\ Oregon Graduate Center. 19600 Von Neumann Dr, Beaverton, \\ OR 97006, U.S.A.
}

Résumé : Nous montrons que l'influence de l'atmosphere résiduelle sur le bruit et la durée de vie des sources d'ions à métal liquide (LMIS) est significative lorsque des electrons secondaires frappent la surface de l'emetteur. Nous proposons une methode de suppression des électrons secondaires lors de la conception d'un canon LMIS.

Abstract: The influence of residual gases on the noise and life time of liquidmetal ion sources (LMIS) has been found to be significant if secondary electrons impinge upon the emitter surface. A straightforward method of preventing electron bombardment of the LMIS in a ion gun structrure is shown.

\section{INTRODUCTION}

Liquid Metal I on Sources (LMIS) are increasingly used in focused ion beams systems for a variety of technically important applications including ion microscopy(1), research in ion lithography(2), direct ion implantation(3), micromachining(4), mask repair(5) and SIMS(1).

Focused ion beam (FIB) systems employing LMIS have become widespread. Measurements of source current and stability (6,7) have revealed the LMIS to be extraordinarily good when operated at ultrahigh vacuum of $10^{-7} \mathrm{~Pa}\left(10^{-9}\right.$ Torr), with noise currents near the shot noise limit. However, many applications of the LMIS do not require ultrahigh vacuum and many of the focused ion beams systems reported to date operate with a vacuum of the order of $10^{-4}$ to $10^{-5} \mathrm{~Pa}$. It is therefore of interest to know. what effect the vacuum will have on stability of operation of an LMIS, what some possible mechanisms are that can effect source stability, and whether the LMIS gun design will have an effect on the stability of the ion source.

We have found that small amounts (partial pressures less than $10^{-5}$ Pa) of hydrocarbon materials in a vacuum system can have significant effect on the stability of an LMIS, especially if secondary electrons produced when the ion beam strikes an aperture near the source impinge on the source structure. It seems that hydrocarbon gases which condense on the source can be cracked by high energy secondary electrons accelerated towards the LMIS by the strong field required for its operation. In fact, the appearence on an emitter after operation in a contaminated environment is as if the reservoir of liquid metal and the tip were contained in a plastic shell. This effect is similar 
to specimen contamination often seen in an SEM or TEM if its vacuLm system is untrapped. Because LMIS are often used in systems with vacuum quality similar to that found in a SEM, we also investigated the effect the LMIS gun design might have on the stability.

Initially a simple bell-jar vacuum system capable of a pressure of about $10^{-4}$ Pa was used. Such a system contains a background partial pressure of carbon bearing gases from pumps. A LMIS gun structure was built which allows the primary ion current and the secondary electrons current to be measured, and also allows the secondary electron current to be suppressed by applying a bias voltage. Further experiments were conducted in a vacuum system capable of $1 \times 10^{-5} \mathrm{~Pa}$ with a controlled leak of acetone vapor.

\section{EXPERIMENTAL PROCEDURE}

An LMIS gun was built with an extraction electrode close to the emitter but with dimensions that prevented any of the primary ion beam from striking the electrode. The ion beam was collected $3 \mathrm{~cm}$ from the LMIS on a metal plate which could be biased at up to 80 volts with respect to the extracting electrode. Positive bias was used to suppress the low energy secondary electron emission produced by the incident ion beam. A diagram of the LMIS structure used is shown in Fig. 1 and the gun structure in Fig. 2. The source was operated at a temperature estimated to be 500-600 $\mathrm{C}$ by Joule heating. At this temperature, most contaminating gases are quickly desorbed if there is no electron beam induced chemical reaction at the surface of the liquid metal.

Ion current striking the collector was amplified by an amplifier with an A.C. coupled output, the front end of which could be elevated to 80 volts with respect to ground. The amplified current was subsequently analysed with a Nicolet 440 B spectrum analyser. In addition, the extraction electrode could be biased negatively with respect to ground while the collector was left at ground potential. Then the ion current could be used to directly drive a strip chart recorder with a bandwith of roughly $0-4 \mathrm{~Hz}$. This prouided striking visual euidence of the effects of electron bombardment on the very low frequency behaviour of the source current. However, the disaduantage of biasing the extraction electrode negatively was that changes in the bias voltage caused the electric field on the emitter, and hence the ion current, to change whenever the bias voltage was varied.

After each spectrum of the noise current was completed, background was substracted by running the spectrum analyser in a mode where counts were substracted from the memory. During background substraction runs, the beall current was turned of by lowering the extraction voltage of the source slightly, while all other system parameters were kept constant. When the higher vacuum system was employed, it was found that the background noise was completely negligible. Unfortunately, it was not possible to measure the partial pressure of the carbon-bearing gases in the bell jar system. However, this was measured in the high vacuum system.

\section{I I EXPERIMENTAL RESULTS}

It is possible to estimate the secondary electron yield for the system extraction electrode/shield plus collector electrode by noting the difference between the collector current when the suppressor is of and the emitter current when the suppressor is on, at least in the range where the true ion current is less than $10 \mathrm{microamps.} \mathrm{Above} \mathrm{this} \mathrm{value,}$ it was not possible to tell what fraction of the ion current was striking the shield as the angular distribution broadened. For this range, the yield was approximately 1.3 electrons per ion. 
The current recorded on the collector plate was strongly affected by the suppressor voltage, typically increasing by more than a factor of two when the secondary electron suppressor was turned off. A voltage of +15 volts on the collector structure was sufficient to suppress most.

(80 \%) of the secondary electrons and no improvement in secondary electron suppression was noted for a suppressor voltage greater than 25 volts. In order to be conservative, in these experiments, a suppressor voltage of +30 volts was used.

An independant power supply was used to provide the suppressor voltage in this study. However, in an actual gun structure for an optical column, the necessary voltage can easily be provided by using a bias resistor in the ion source extraction voltage return line, to maintain the first downstream aperture at around +25 volts with respect to the extraction electrode. This method was employed in the $200 \mathrm{~nm}$ resolution beam column in this laboratory, and was found to have a negligible ion optical effect. A 50 volt zener alode was connected in parallel with the resistor to prevent the bias voltage from reaching values dangerous for the resistor if for some reason the extraction current were increased to some hundreds of microamps.

It was found that approximately $80 \%$, of the secondary electrons produced by the ion beam at the collector would return to the emitter, with the remainder striking the extractor electrode. The effect of the secondary electron current is dramatically shown in Fig $3 A$ and $3 B$. Here the side " $A$ " of the extraction electrode represented on Fig. 2 is shown after 3 hours of running time with the suppressor of $(B A$ ) and on ( $3 B$ ), with the carbonaceous contamination quite evident. An Auger analusis showed the contamination to be composed primarily of $C$ and $D$, with traces of material sputtered from the collector electrode. This is consistent with the composition of the poluphenolester diffusion pump fluid used in the vacuum system. The thickness of the contamination layer was measured to be approximately $60 \mathrm{~nm}$ apter one hour of operation at a source current which totalled 10 microamps of ions with no electron suppresion.

The A.C. component of the current in the frequency $0.125 \mathrm{~Hz}-50$ $\mathrm{Hz}$ was measured with the spectrum analyser. In this case, the extraction electrode was grounded and the collector biased at +30 volts when the suppressor was used. A spectrum taken with the suppressor of is shown in Fig 4A where it can be seen that the noise current is essentially contained below $30 \mathrm{~Hz}$, with most of the power falling below $15 \mathrm{~Hz}$; when the suppressor was turned on, the noise current fell by approximately a factor of 1.4 compared to the value measured when the suppressor was turned of $\mathrm{f}$, in the bandwidth $0.125-$ $50 \mathrm{~Hz}$ as shown in Fig. $4 \mathrm{~B}$.

This experiment was repeated with a turbo-pumped system having a base pressure of about $1 \times 10^{-6} \mathrm{~Pa}$. In this case both air and acetone were leaked into the system, acetone at a pressure of $3 \times 10^{-6} \mathrm{~Pa}$. It was again found that the carbon bearing gas caused a higher noise current when there was no secondary electron suppression; the suppression factor was about 2.2. The noise current due to acetone was measured to be about 4 times higher than that for air with no secondary electrons suppression, even with the air pressure 3 times higher than the acetone. When the secondary electrons were suppressed, the noise spectra were essentially identical. 


\section{DISCUSSION}

We have found that a large fraction of the secondary electrons produced by the ion beam striking an electrode several centimeters distant from a LMIS, return to the source. Based on micrographs of the source and examination of the nearby extraction electrode, it is evident, as was found earlier by Swanson (8), that the secondary electrons promote the formation of carbonaceous films if there is any feedstock of hydrocarbons in the vacuum system which can condense on surfaces. We have found that the low frequency portion of the noise current of an LMIS is significantly affected by this process. We have also noted that the operationnal life of the emitter is strongly affected by the carbonaceous film. The effect of carbon-free air on the noise current is less by several times.

since the current from an LMIS is produced at a very tiny cusp with extremely low mass in a very high electric field at the end of a Taylor cone (9) (10), it is difficult to see why only low frequency fluctuations in the current would be produced if the mechanism were only the direct contamination of the cone. It seems more likely that the low frequency fluctuation are caused by interference with the flow of liquid metal up the shank of the emitter towards the cone. For some distance along the shank of the emitter the thikness op the liquid metal is only of the order of some nanometers. The impact of a contamination layer on this thin film could easily cause hydrodynamic instabilities in the cone. The supposition that it is contamination of the emitter structures and not just the Taylor cone which causes problems. is strengthened by calculations of saitou (11) who has shown that in the case of electrons pield emission, the trajectories of almost all ions produced by the electron beam carry them to the gmitter shank, not the tip. Additionally, calculations of the flow rate of liquid metal along the shank (12) indicate that the time constant for events dependant on the flow should be of the order of 0.05 second, which is the order of magnitude of the frequency current fluctuations we have actually seen.

\section{v. GONCLUSIONS}

It is clear that secondary electron bombardment of the LMIS can cause a significant increase in the low frequency current fluctuations of the ion beam, if there are any contaminant vapors present in the vacuum system that can be polymerised by high energu electrons. Therefore, if an LMIS is to be operated in conditions where there may be such contaminants present, it would be well to arrange for some sort of secondary electron suppression in the ion gun structure.

The authors would like to thank J. Gierak for his assistance in carrying out the experiments and $P$. Ossart (CNET) for performing the Auger analysis

\section{References}

1 R. Levi-Setti, Y.L. Wang and B. Grow, Proc. of IFES 84, Journ. de Phys. 45, C9, 197 Dec.1984.

2 R.L. Seliger, J.W. Ward, and R.L. Kubena, App. Phys. Lett. 34, 310 (1979).

3 E. Miyauchi, H. Arimoto, H. Hashimoto and T. Utsumi, J. Vac. Sci. Technol: B1 (4); 1113 (1983). 
4 J. Puretz, R.K. DeFreez, R.A. Eliott and J. Orlopf, Electron. Lett, 22, 700 (1986).

5 A. Wagner, SPIE, J. 393, 167 (1983).

6 L.W. Swanson, C.A. Schwind, A.E. Bell and J.E. Brady, J. Vac. Sci. Technol.16 (6), 1864 (1979).

P.P.D. Prewett in United Kingdom Field Emission Group Meeting, Oxford, 6-11-1984.

8 L.W. Swanson, Private communication.

9 D.R. Kingham and L.W. Swanson Proc. of IFES 84, Journ, de Phys. 45, C. 133 (1984).

M. Chung, P.H. Cutler, T.E. Feutehwang, E. Kazes, N.M. Miskousky Proc. of IFES 84, Journ. de Phys. 45, C9, 153, (1984).

10 0. Benassayag, P. Sudraud, B. Jouffrey, Ultramicroscopy, 16, 1 (1985).

11 N. Saitou, Surf. Sei. 66,346 (1977).

12 G. Benassayag, Thesis, Orsay/Toulouse, 04-1983.

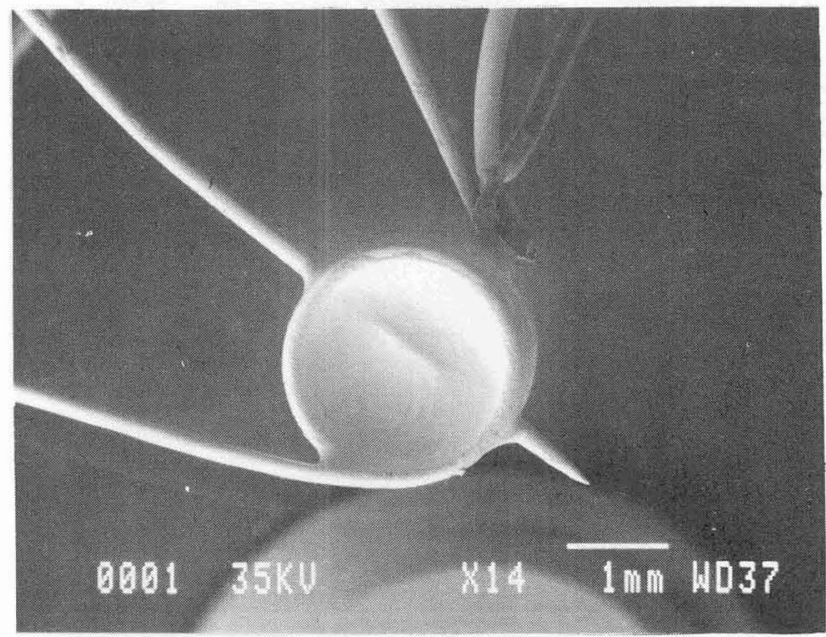

Figure 1 . SEM Mi crograph of the liquid metal ion source configuration employed. Heating current can be passed through the $W$ coil, which holds a large reservoir of $B a$. The $W$ emitter substrate had an end radius of approximately 10 micrometers. 


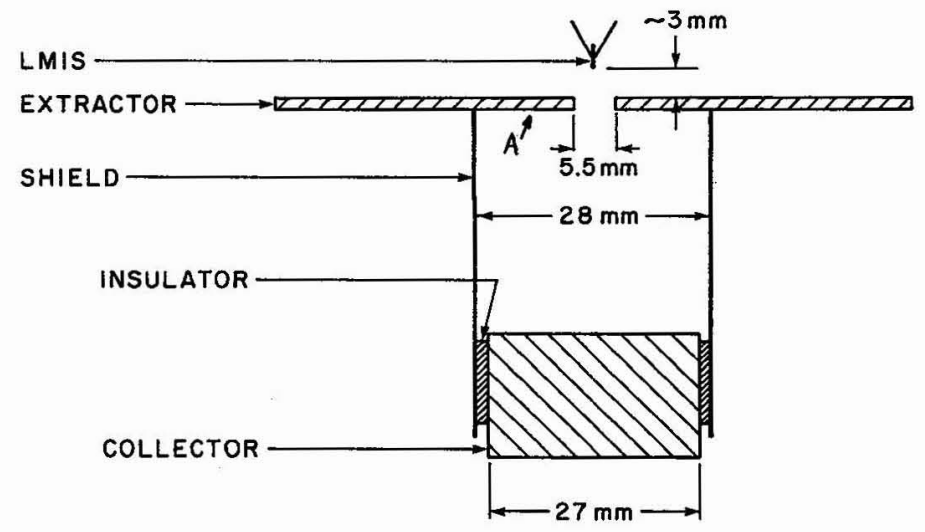

LMIS TEST STRUCTURE

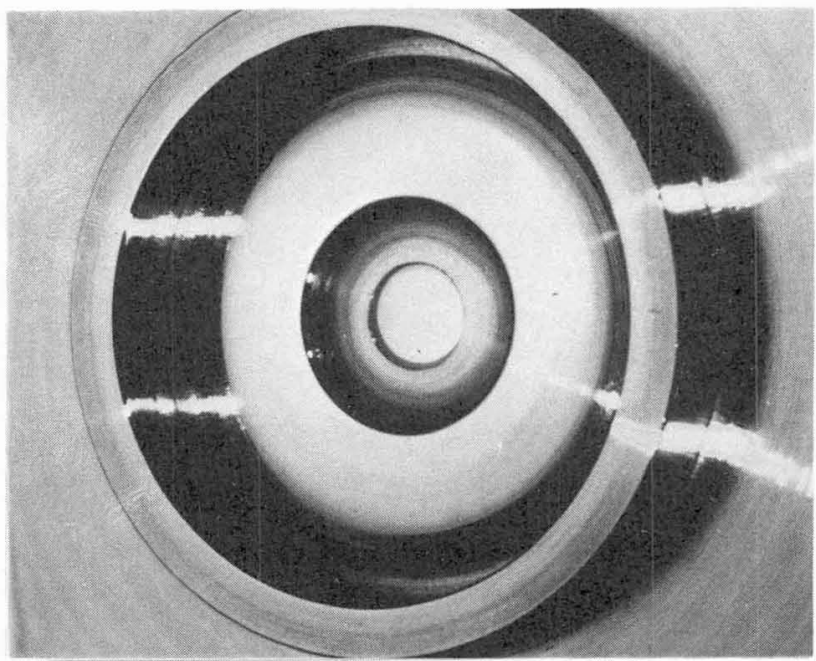

3A

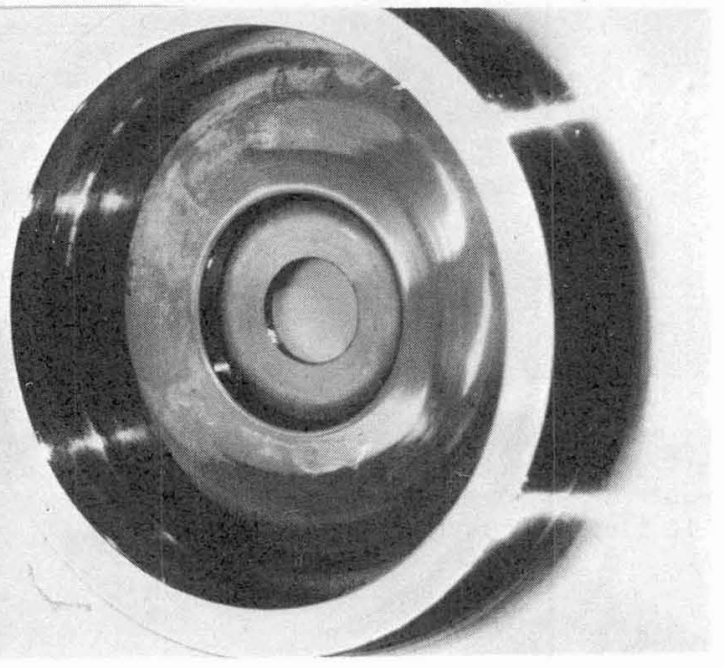


Figure 2. Schematic aiagram of the LMIS gun structure used in this study. The LMIS (see Fig. 1) was located approximatively 3 mm from the extraction electrode, the aperture of which substended a half angle of 43 degrees with respect to the emitter tip. The shield was electrically connected to the extractor and insulated from the collector.

Figures $3 A$ and $3 B$. The area of the extraction electrode marked " $A$ " in fig 2 after 3 hours of operation with 10 microamps ion current without (4A) and with (4B) secondary electrons suppression. The vacuum was $10^{-4}$ Pa, contaminated with pumped oil.

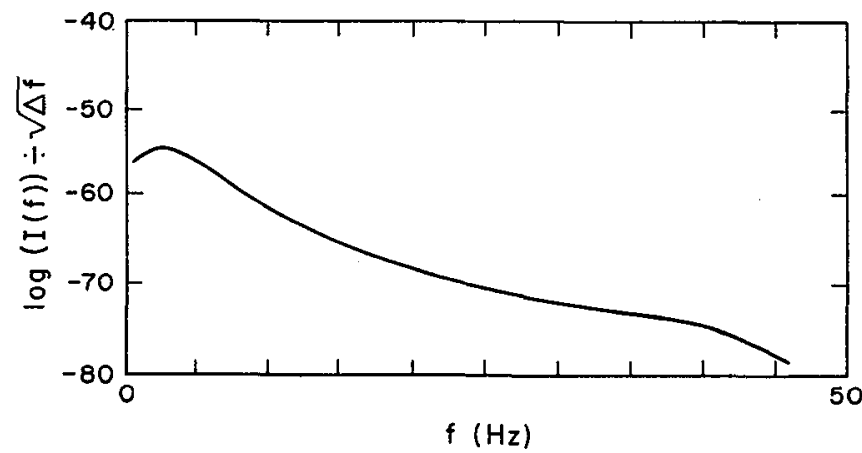

A

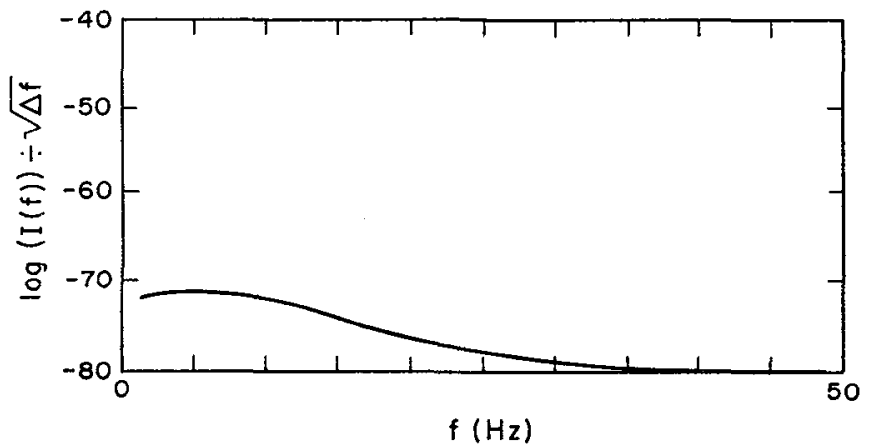

B

Figures $4 A$ and $4 B$. The spectral density functions for the total ion beam current without secondary electrons suppression ( $3 A$ ) and with secondary electrons suppression ( $3 B$ ). 